\title{
J. X. Carvalho de Mendonça e a Faculdade de Direito de São Paulo
}

Proclamada a República, em 1889, como acontece no período inicial dos regimes novos, instaurados por efeito de movimentos revolucionários, ainda que incruentos, cuidou-se, como era natural, da renovação do ensino, principalmente do ensino superior. Bastava a circunstância de que a pasta, que o superintendia, tivesse sido confiada a BenJamin Constant, para que não se retardassem as providências no sentido de despí-lo de seu passadismo, que foi glorioso.

Deu-se a refórma do ensino nas Faculdades de Direito, pelo decr. n. 1.232-F, de 2 de janeiro de 1891, passando a ministrar-se em tres cursos: o de ciências jurídicas, o de ciências sociais e o de notariado.

Dividiu-se o curso de ciências jurídicas em quatro séries, a saber: primeira série, duas cadeiras - a de filosofía a história do direito e a de direito público e constitucional; segunda série, quatro cadeiras - a de direito romano, a de direito civil, a de direito comercial e a de direito criminal; terceira série, tres cadeiras - a de medicina legal, a de direito civil e a de direito comercial; e quarta série, quatro cadeiras - a de história do direito nacional, a de processo criminal, civil e comercial, a de noções de economia politica e direito administrativo e a de prática forense.

Desdobrou-se o curso de ciências sociais em três séries: a primeira, com duas cadeiras - a de filosofia e historia do direito e a de direito publico e constitucional; a segunda, com três cadeiras - a de direito das gentes, diploma- 
cia e tratados, a de economia politica e a de higiêne pública; e a terceira, com tres cadeiras - a de ciência da administração e direito administrativo, a de ciências das finanças e contabilidade do Estado e a de legislação comparada sôbre o direito privado.

Confinou-se o curso de notariado em duas séries, sendo a primeira série de duas cadeiras - a de explicação sucinta do direito pátrio, constitucional e administrativo e a de explicação sucinta do direito pátrio, civil e comercial; e a segunda série com igualmente duas cadeiras - a de explicação sucinta do direito pátrio processual e a de prática forense.

Tresidobrado dêsse modo o curso do bacharelado, acresceu-se o número de professores. Vinte e dois seriam os catedráticos e seis os substitutos.

Por efeito de concursos, anteriormente realizados, foram nomeados professores catedráticos ou passaram a reger as novas cadeiras Brasilio Rodrigues dos Santos, Frederico José Cardoso de Araujo Abranches, João Mendes de Alameida Junior, Pedro Augusto Carneiro lessa, Brasilio Augusto Machado de OliveIra, transferindo-se da Faculdade de Direito de Recife Manoel Clementino de Oliveira EsCOREL.

Dada a dificuldade de preenchimento das demais cadeiras por concurso, foram nomeados sem que a êste se houvessem submetido Uladislau Herculano de Freitas, José Xavier Carvalho de Mendonģa, antonto Amancio Pereira de Carvalho, Augusto Nogueira da Rocha Mrranda, Jesuino Ubaldo Cardoso de Melo, Antonio Januario Pinto Ferraz, Aureliano de Souza E Oliveira Coutinho, Jose Luiz de Almeida Nogueira, José Machado de Oliveira, Alfredo de Barros Oliveira Lima e Manoel Pedro Vilaboim, todos juristas e medicos dois deles, de muito e alto conceito pelos seus méritos e renomes assim no pretório como na administração e na politica.

Não receberam os estudantes essas nomeações por simples decretos, mercê de munificência governamental, sem 
o seu protesto; e no meio deles, com natural e viva repercussão fóra das arcadas da Faculdade de Direito, surgiram críticas acerbas.

Compreendia-se. A forma normal de ascender ao magistério superior era o concurso. Que cada um, por via dele, conquistasse a cátedra! Era o que desejavam os estudantes. A investidura devia resultar de provas de capacidade e não de benesses do favoritismo do alto. Daí a revolta dos moços. Ajustaram-se êles, a princípio, em ausentarem-se das aulas dos "lentes que entraram pelas janelas", como então diziam. O alvoroço prolongou-se por muitos dias...

Os lentes por decreto eram vaiados nas arcadas seculares; e os protestos sucediam-se.

Tal intensidade tiveram êles, que o govêrno da República fez expedir o decr. n. 54, de 21 de março de 1891, nestes termos:

“O Presidente da República dos Estados Unidos do Brasil resolve que, se os lentes catedráticos e substitutos, professores e preparadores nomeados sem concurso, dentro do prazo de um ano, a contar da data da posse, fôrem declarados inhábeis para o magistério pelas congregações das respectivas escolas ou faculdades, em cujas votações para êsse fim não poderão êles tomar parte, sejam seus lugares postos em concurso".

Esse decreto, referendado pelo ministro da Justiça JoÃo Barbalho Uchoa Cavalcanti, que seria depois ministro do Supremo Tribunal Federal, e que veio a destacar-se como o grande comentador da Constituição Federal de 1891, de certo modo acalmou os estudantes exaltados e operou como refrigério aos ânimos em sobressalto dos aquinhoados com as cátedras; mas levou um dos professores nomeados a, sem perda de tempo, formular êste requerimento: 


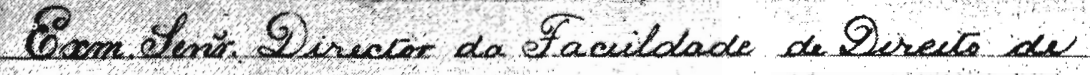
Slaiderulo.

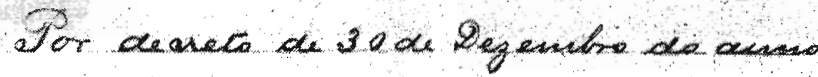

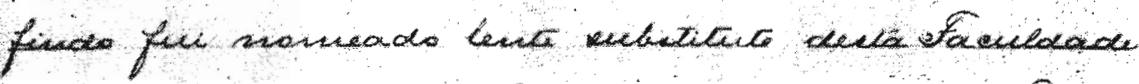

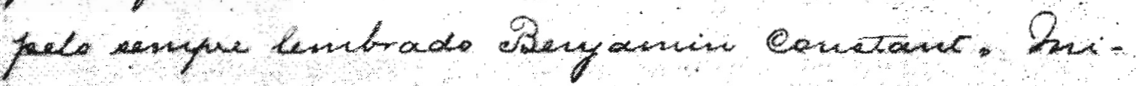

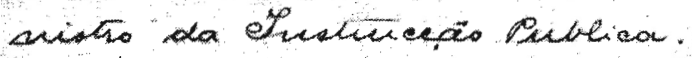

- Onin 16 de foveiro chets ania

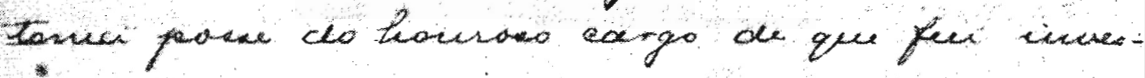

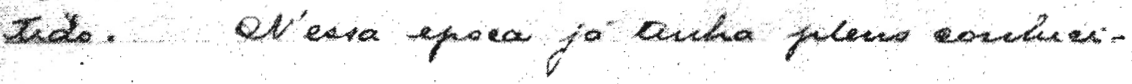

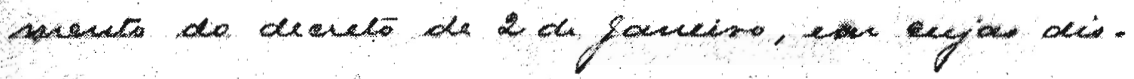

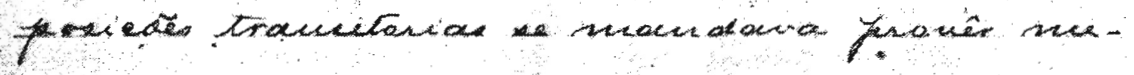

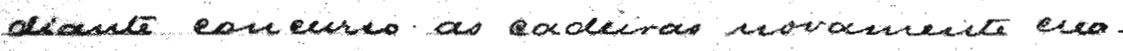
Las.

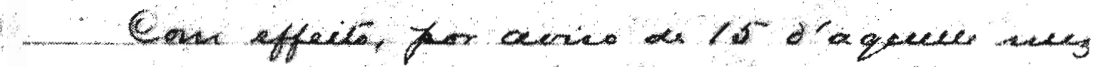

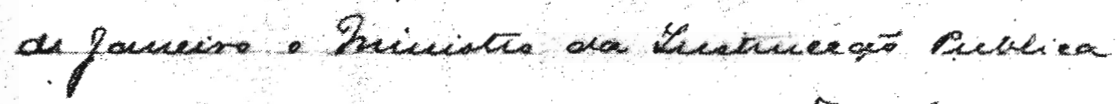

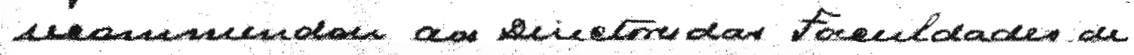

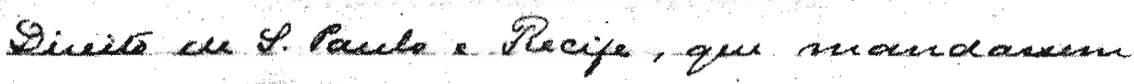

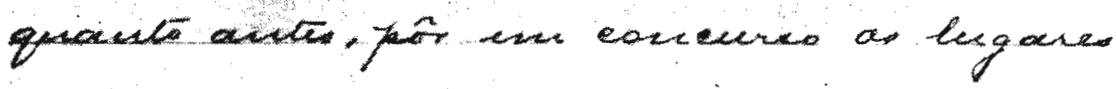

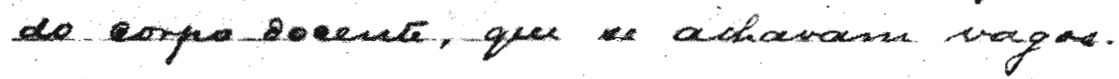

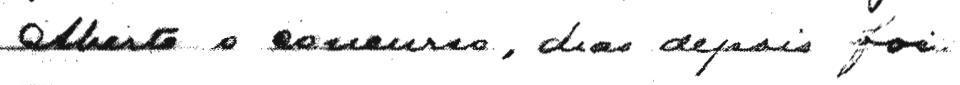




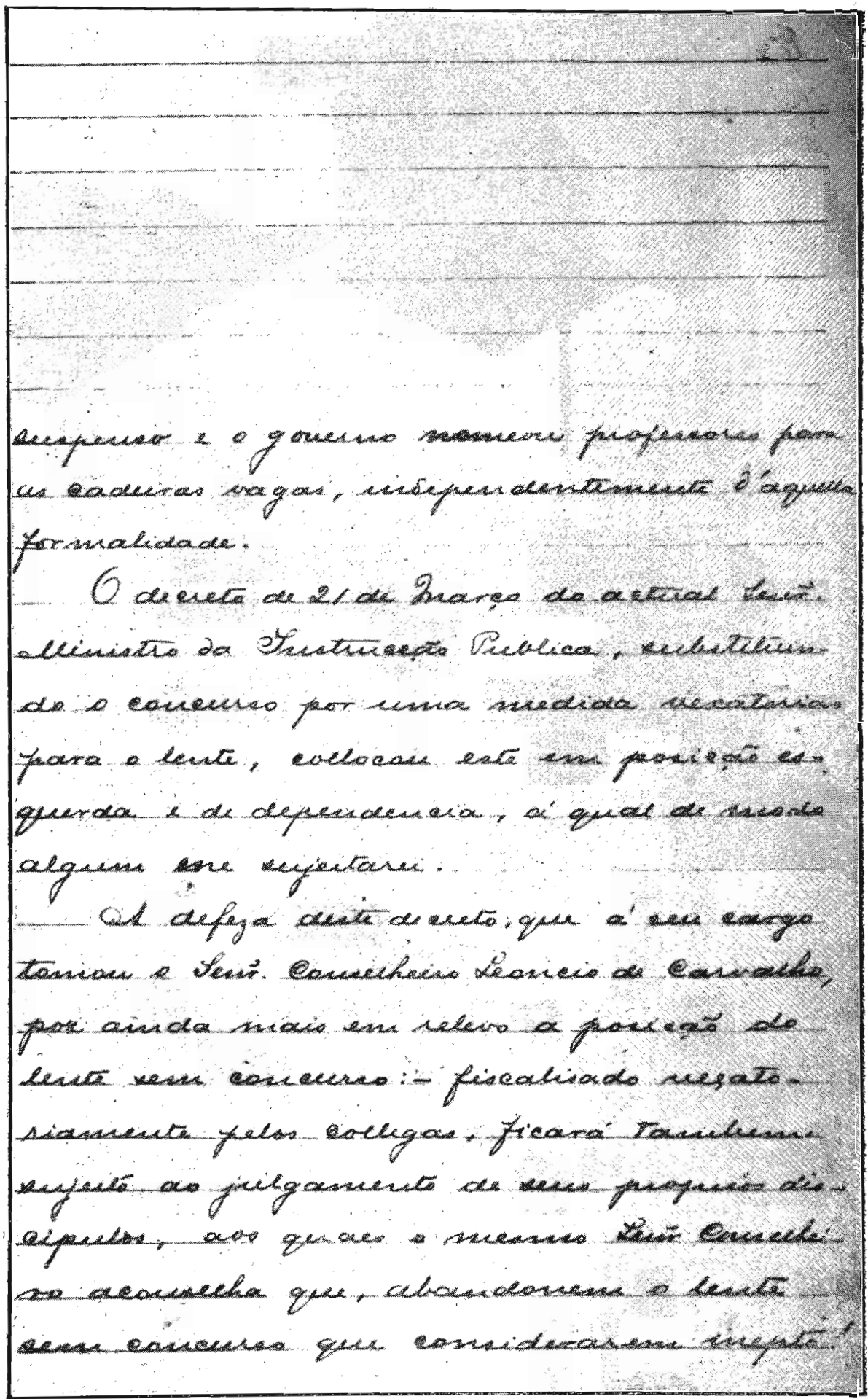




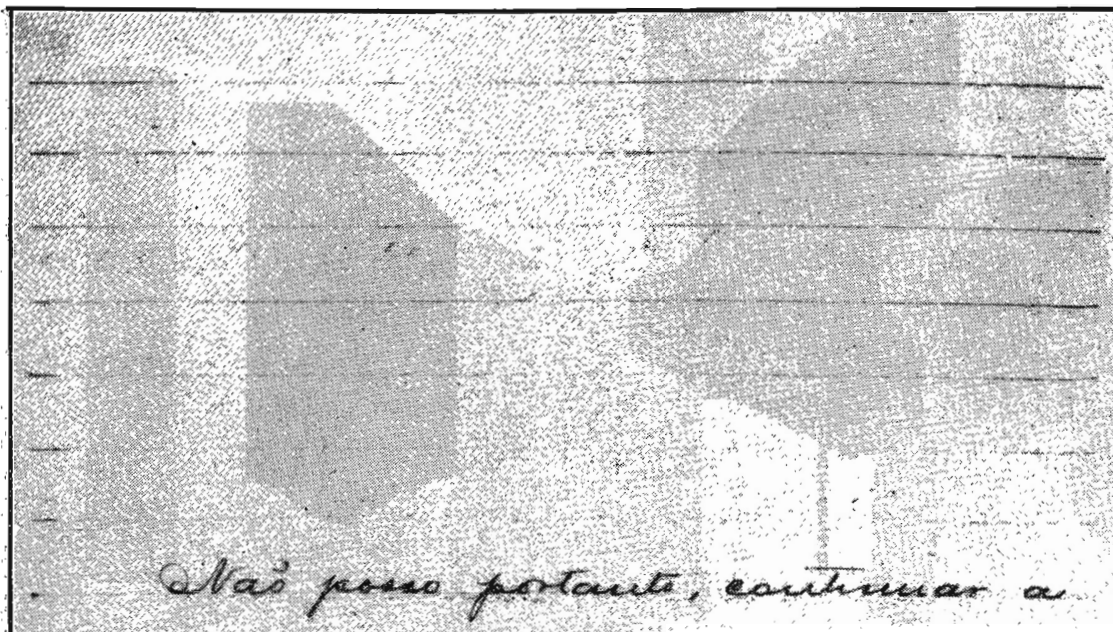
upren o carge de levul dubutikuts denta schete tawhad.

Seen a U. $\varepsilon_{3}$ a ne agne hevar al conle chunto dowerno genai, que. neto dato. tuh nevignida o cargs fana que fen womicado for deveto do Sa ds Dejenebro do anmo panoda.

efacede roterimada

Sas Saish 91 da Dareo d 1891

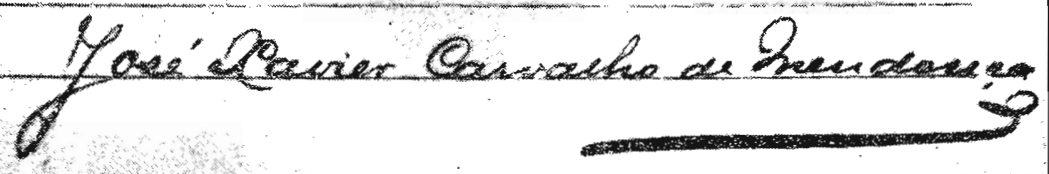


A atitude, que J. X. Carvalho de Mendonça assim tomou, não repercutiu, como devera, no seio da Congregaçâo da Faculdade de Direito, em boa parte constituida pelos professores que haviam sido nomeados por decreto. Não chegou siquer seu requerimento a ser lido quando reunida ela, talvez porque o próprio diretor o houvesse encaminhader ao Ministro da Instrução Pública, Correio e Telégrafos, sem dar-lhe dela conhecimento oficial.

Serviu, no entanto, para que, em Congregação de 4 de abril de 1891, apresentasse JoÃo MonteIro a seguinte indicação :

"Considerando que à Congregação compete manifestarse diretamente acerca da atual questão da nomeação de lentes sem concurso, pois cumpre-lhe guardar ciosamenteas suas prerrogativas de juiz, e zelar dos créditos cientificos da Faculdade;

"Considerando que os lentes, nomeados ultimamente sem concurso, são conhecidos - uns por haverem ocupado, com brilho, elevados cargos públicos, e outros, por já haverem sustentacio téses para doutoramenta e para concurso, sendo aprovados, e propostos ao Govêrno;

"Considerando já haver a Congregação admitido a tomar posse, sem reclamação, os lentes, nomeados no anopassado, sem concurso;

"Indico que a Congregação dê por habilitados os referidos lentes, e admita-os a tomarem posse".

Achava-se sôbre a mêsa a manifestação de protesto dosestudantes. Propôs o professor Vieira de Carval ho que dela se conhecesse, embóra lhe parecesse que a Congregaçĩo nada mais poderia fazer; e era esta:

"Reunidos em uma das salas do Liceu de Artes e Oficios, no dia 6 do corrente, os acadêmicos de Direito incumbiramnos de, em seu nome, agir de modo a que não se efetuassem as nomeações de lentes, para as cadeiras vagas, na Acade- 
mia, nomeações já publicadas como certas, por alguns órgãos da imprensa.

"No intuito de dar cumprimento à delegação recebida, entendemos ser medida acertada, e de alto alcance, para salvaguarda de nossos interêsses ameaçados, dirigir-vos uma representação, solicitando o vosso poderoso auxilio para defesa de nossa causa.

"Como bem compreendeis, o futuro da Pátria Brasileira, a consolidação da República, a garantia de todos os direitos e de todas as liberdades, dependem essencialmente da direção, a que fôr submetido o ensino, de modo que, descurado êste, teremos como consequência o desprestigio dos titulos cientificos, o aniquilamento da intelectualidade dos moços, e, como corolário de tantos males, uma verdadeira desgraça nacional - a falta, em tempo não mui remoto, de pessoal idôneo para direção dos altos negócios da República. Ora, sucede que, entre os cidadãos, cujas nomeações para lentes são anunciadas, muitos há aos quaiis falecem aptidões para dar ao ensino juridico essa indispensavel, e salutar direção, de que temos falado.

"Assim sendo, dariamos prova, nós, os moços estudantes, de decadência moral e intelectual, ou de indiferença, altamente condenavel, se assistissemos impassivelmente essa doação, que se está fazendo, de cadeiras, até hoje tão brilhantemente ocupadas por eminentes jurisconsultos. E' por isso que, agindo dentro da lei, confórme nos ordenam nossos deveres cívicos, e o respeito às autoridades constituidas, dirigimos nossas primeiras solicitações aos poderes competentes, afim de que êles forneçam de pronto remédio aos males, que dolorosamente nos afetam.

"Os interêsses do ensino superior, ora ameaçados, sendo comuns aos mestres e aos discipulos, estamos conscios de que é mister estabelecer, entre uns e outros, uma forte solidariedade, para que êles tenham uma garantia pronta 
e eficaz. Contamos, pois, com o poderoso concurso da vossa palavra autorizada.

"Saúde e fraternidade.

"São Paulo, 14 ide março de 1951. - Lafayette Chagas. - Antonio Pinto. - Virgilio Caldas".

A representação dos estudantes teve o apoio de Brasilio Rodrigues dos Santos, que, no entanto, apresentou proposta substitutiva da de JoÃo MonteIro, declarando que a Congregação, se tivesse sido ouvida, teria concordado com as nomeações do Desembargador Aureliano Coutinho e dos Doutores Rodrigo Lobato, Campos Toledo, Mrranda Azevedo, João de Araujo, Pinto Ferraz, Jesuino Cardoso, Oliveira Lima, Augusto Miranda e Amancio de Carvalho, por julgálos habilitados, entendido, entretanto "que julga essencial, para a boa organização e progresso do ensino, que os lugares do corpo docente sejam providos, ou mediante indicação prévia da Congregação, ou por meio de concurso, na fórma do regulamento vigente de 2 de janeiro" Essa indicação teve o apoio de Almeida Nogueira, Abranches, Brasilio dos Santos, Vicente Mamede, João Monterro e Leoncio de Carvalmo, abstendo-se Herculano de Freitas, Vieira de Carvalho, Brasilio Machado e João Mendes Junior.

Decidiu a Congregação, ademais, aprovar a representação dos estudantes, por seus fundamentos, mas absteve-se de encaminhá-la ao Govêrno.

Tão nobre foi o gesto de J. X. Carval.ho de Mendonça resignando, em 31 de marco de 1891, o cargo de professor para que fora nomeado em 30 de dezembro de 1890 , quão prejudiccial ao ensino do Direito. 0 jurisconsulto eminentissimo, que veio a ser, pelo consenso geral do país, o maior comercialista brasileiro, teria dado ao ensinamento da disciplina relevo extraordinário. Foi êle o único na renúncia. Como Manoel Pedro Villaborm também foi o único a submeter-se a concurso, mesmo depois de nomeado.

Não chegaram Rodrigo Lobato e JoÃo de Araujo a tomar posse. 